\title{
Development of Citizen's Charter to Improve the Service Provision at a Regional Health Services Directorate in Sri Lanka
}

\author{
Rajakaruna, I.M.S.M. ${ }^{1}$, Krishanth, M.D.A. ${ }^{2}$, Pathirage, I.D. ${ }^{3}$, Arnold, S.M. ${ }^{4}$ \\ 1,2,3,4 Ministry of Health, Sri Lanka
}

\begin{abstract}
Introduction: Citizen's charter is a means to improve service delivery processes and foster greater customer satisfaction. Unacceptable delays in providing services by the Office of Regional Director of Health Services, Kurunegala (RDHSK) and subsequent re-visits had created customer dissatisfaction. A citizen's charter was developed to improve the service provision at RDHSK.

Methods: Ten services being provided to nursing officers by the Establishment Branch (EB) of RDHSKwere prioritized for incorporating in the charter. The services were mapped and redesigned, and deficiencies were dealt with developing and implementing the charter, its sub-components and supplementary interventions. The charter and sub-components were designed and implemented as per the Public Administration circular issued in 2008, adopting the participatory approach. To enhance the effectiveness of charter, several supplementary interventions were designed. A focal point, a steering committee, and monitoring, review and appraisal mechanisms were established. Documents that need access by nursing officers were kept at their workplaces in addition to RDHSK and its website. New developments were effectively communicated to the staff of RDHSK through training and to service recipients through multiple routes.
\end{abstract}

Results: The new developments included the citizen's charter, its sub-components and supplementary interventions. Subcomponents include summary charter and feedback and response system with complaint and feedback formats, feedback box and feedback and response register. The supplementary interventions comprise document submission checklists, compilations of formats to be filled for receiving services with a relevant checklist on the top, guidelines for nursing officers and their work institutions on new developments, and a booklet on work steps for MAs providing services at EB.

Conclusion: The participatory approach, stakeholder involvement throughout, wider publicity of charter among service recipients and service providers, effective feedback and response system, and mechanisms for monitoring, evaluation, review and appraisal of the charter are useful means to successfully develop, implement and sustain charters.

KEYWORDS: Citizen's Charter, Monitoring, Response system, Service delivery

\section{INTRODUCTION}

The Office of Regional Director of Health Services is the administrative focal point for health institutions including hospitals and Medical Officer of Health Offices offering comprehensive public health services in each district of Sri Lanka. The Office of Regional Director of Health Services, Kurunegala (RDHSK) is the administrative focal point in Kurunegala District and has four branches. Out of which, the Establishment Branch (EB) has the largest customer interface of 5044 health workers in 63 categories of 129 health institutions coming under the directorate.[1] It deals with routine but critical personal file-related services. Consequently, catering with effective and efficient services to a large number of external customers using limited resources has been a challenge for the management of RDHSK.

Lack of explicit service standards for the EB of RDHSK results in unacceptable delays in service provision and frequent unwarranted visits. Ineffective two-way communication between the EB and service recipients builds a dilemma among service recipients on documents that need to be submitted along with service requests, and nursing officers had to visit the RDHSK to collect application formats. Subject officers accepted requests without checking for the completeness of documents. They had no mechanism of referring lengthy lists of documents for crosschecks, and thereby, missing one or more documents resulted in rework and 


\title{
International Journal of Current Science Research and Review
}

\author{
ISSN: 2581-8341
}

Volume 05 Issue 01 January 2022

DOI: 10.47191/ijcsrr/V5-i1-31, Impact Factor: 5.825

IJCSRR@ 2022

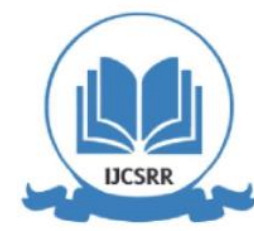

www.ijcsrr.org

unacceptable delays in service provision. When the subject officer is on leave, the covering up officer does not know the work steps to be followed making the situation worse. Besides, there is no existing mechanism to tackle customer grievances on poor service provision, and the nursing officers' suggestions were never sought for service improvements. These factors collectively create dissatisfaction among service recipients of EB. Therefore, it is important to improve the service provision from the RDHSK by devising well-targeted and effective initiatives.

Citizen's charter is a useful way to fine-tune service delivery processes, improve overall performance and foster greater customer satisfaction.[2] A citizen's charter is a voluntary public commitment made by a service provider to uphold standards of quality, transparency and accountability.[3] It sets out the services provided by the institution, a list of documents to be submitted and other requirements to be fulfilled along with the written request, standards of service that customers can expect, contact details of responsible persons in case the citizen needs help and makes complaints or suggestions.[4,5] Charters make administration accountable and citizen-friendly, ensure transparency, take measures to improve customer service, adopt a stakeholder approach and save the time of both administration and citizen.[6] Its aim at continuously improving customer satisfaction was the key to success and spread throughout the world.[7] Encouraged by achieving great success and yielding desired results of the first articulation and implementation of citizen's/client's charter by the United Kingdom in 1991, governments of both developed and developing countries are increasingly adopting the concept.[8,9] Sri Lankan Government initiated implementing the concept in 2008.[4]

Charter initiative has contributed to great improvements in public service delivery of many countries. However, this goal is not always achieved due to challenges in the design and implementation stages. As charters are not legally enforceable, it needs the commitment of the organization for successful implementation.[9] Quality, choice, standards, value, accountability and transparency are its originally framed six principles that ensure citizen-centred service delivery.[6] A charter essentially consists of the 3 C's: Customer-driven service standards, Communication of standards for all potential customers and Control of the organization's activities and can be for all or selected few services of the organization. Good charters usually cover the services with the larger public interface.[7] Charters can easily be combined with other quality improvement tools like customer satisfaction surveys and process management instruments.[10]

Thomassen et al [11] conclude that successful implementation of charters requires a change management process that addresses both structures/systems and cultural aspects. Lack of stakeholder consultation due to the top-down approach adopted in formulating, simply listing out all departmental services without prioritizing, poor service delivery standards and underperformance, inadequate designing and implementation capacity of owned departments, poor publicity campaign leading to low awareness among potential customers and lack of interest among stakeholders were the important drawbacks which should be given due consideration for effective designing and implementation. $[6,9,12]$ Instead of trying to reform all processes at once and encounter massive resistance, breaking the tasks into small components and tackling them one at a time is advised.[4]

The components of a typical citizen's charter include vision and mission statements, details of services delivered by the organization, details of clients/recipients of services, details of services provided to each client group, service standards/quality, requirements to be fulfilled by the client/service recipient, legislative and other provisions relating to obligations of the service providers and rights of the service recipients, details of grievance lodging and redressal mechanism and how to access it, expectations of the clients/recipients of services.[4]

\section{METHODS}

Citizen's charter and supplementary interventions were designed and implemented at EB of RDHSK from September to December 2019 adopting the participatory approach. As the processes of and requirements for personal file related services were unique for different customer categories, the necessity of separate charters for separate categories was understood. Based on the size of the customer interface, the volume of issues faced by service providers and feasibility, the category of nursing officers was chosen as the top priority for developing the charter. The topmost seven services resulted in $81.9 \%$ of visits to EB based on data gathered from nursing officers, and three other services selected by RDHSK staff based on urgency, importance and volume of issues were prioritized for incorporating in the charter. These services included; obtaining a formal letter of appointment, registration under 


\title{
International Journal of Current Science Research and Review
}

\author{
ISSN: 2581-8341
}

Volume 05 Issue 01 January 2022

DOI: 10.47191/ijesrr/V5-i1-31, Impact Factor: 5.825

IJCSRR@ 2022

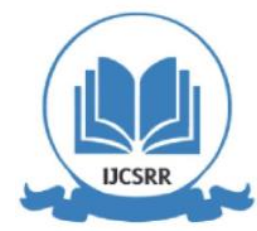

www.ijcsrr.org

widows'/widowers'\& orphans' pension scheme, approving annual increment, confirmation in the service, Grade II promotion, Grade I promotion, Supra grade promotion, recommending foreign leave with pay, obtaining prior approval for the retirement, and the retirement.

The routine process of providing the above services was mapped using the qualitative data gathered through observation and from the service providers who take part in each process. Then the processes were studied extensively to identify deficiencies in service provision. (Figure 1)

Formulation and implementation of the citizen's charter proceeded as guided by the circular on the introduction of the citizen's charter issued by the Ministry of Public Administration in 2008. According to the circular, summary charter, and feedback and response system consisting of complaint and feedback formats, feedback box and feedback and response register were subcomponents of citizen's charter. Several supplementary interventions were also designed: document submission checklists, a compilation of formats to be filled for receiving each selected service by applicants with a relevant checklist on the top, guidelines for nursing officers and their work institutions on new developments, and a booklet on work steps for Management Assistants (MAs) who take part in providing selected ten services at EB.

Development and implementation of citizen's charter for the selected ten services offered to nursing officers at EB of RDHSK proceeded through five principal stages: formulation of the charter; promotion of the charter; service recovery; monitoring; and evaluation and improvement.[4]

\section{Formulation of the citizen's charter}

Formulation of the citizen's charter began with the preparation of a work manual and thereafter the preparation of the citizen's charter. A core group of seven members consisting of four MAs providing services to nursing officers at EB, the Senior Management Assistant (SMA), the Administrative Officer (AO) and the Deputy RDHS formulated the work manual and the charter with the consensus of all relevant stakeholders.

Initially, the core group identified requirements to be fulfilled by the nursing officers in terms of each selected service of the EB such as forms to be filled and documents to be submitted. The workflow of the services was drawn up considering preparations, recommendations, certifications, approvals etc. along with officers responsible for each point. The delays between points were identified and the possible ways to minimize delays were examined. Possibilities for delegation were considered. Repetitions and redundant steps were eliminated. Quality requirements or standards to be met at each point were identified. Finally, the core group came up with a redesigned process. The time required between points of the workflow was assessed keeping a margin for service contingencies. Then the total time duration needed to deliver each service was assessed. Nursing officers and staff of RDHSK were consulted on the total time duration needed to deliver each service before finalizing it.

The draft charter was created extracting the services offered, requirements to be met by the nursing officers to receive the service and time durations required to deliver each service (service standards) from the work manual. The charter indicated the remedies for service recipients in cases of non-adherence to the standards and the commitments enshrined in the charter. Effective feedback and response system consisting of complaint and feedback formats, feedback box and feedback and response register was established for receiving complaints/suggestions of service receivers and detailed in the charter. The complaint and feedback formats were designed according to the sample format annexed to the public administration circular. Complaints and feedback formats were placed at the institute's main office, the in-charge nursing officer's office and the 'feedback box' located at RDHSK. The feedback box was made available at the entrance of RDHSK adjacent to the displayed summary charter. The feedback and response register was designed with separate sections for complaints, suggestions and praises. Each section consisted of columns dedicated for the serial number, service (1-10) of the charter relating to the feedback, health institution from which the feedback was received, date of receipt, date of review, date of reply to the customer who gave the feedback, complaint/suggestion/praise and the action taken regarding the feedback. The draft charter was made as per the format given along the circular incorporating the vision, mission and commitment of the EB, selected ten services, the duration the RDHSK takes to fulfil the requested service (service delivery standard) in days, laws, codes and regulations etc. relevant to each service, contact details (telephone and fax numbers) of relevant personnel to be contacted in case the service receiver needs any help, documents need to be submitted by the 


\section{International Journal of Current Science Research and Review}

ISSN: 2581-8341

\section{Volume 05 Issue 01 January 2022}

DOI: 10.47191/ijcsrr/V5-i1-31, Impact Factor: 5.825

IJCSRR@ 2022

nursing officer and other requirements need to be fulfilled by the nursing officer to receive the requested service and detailed complaints and suggestions system. The draft charter was circulated among the staff for comments/suggestions and finalized following modifications to include suggestions. The charter was made as simple as possible in Sinhala and translated into English by the principal investigator and to Tamil by a

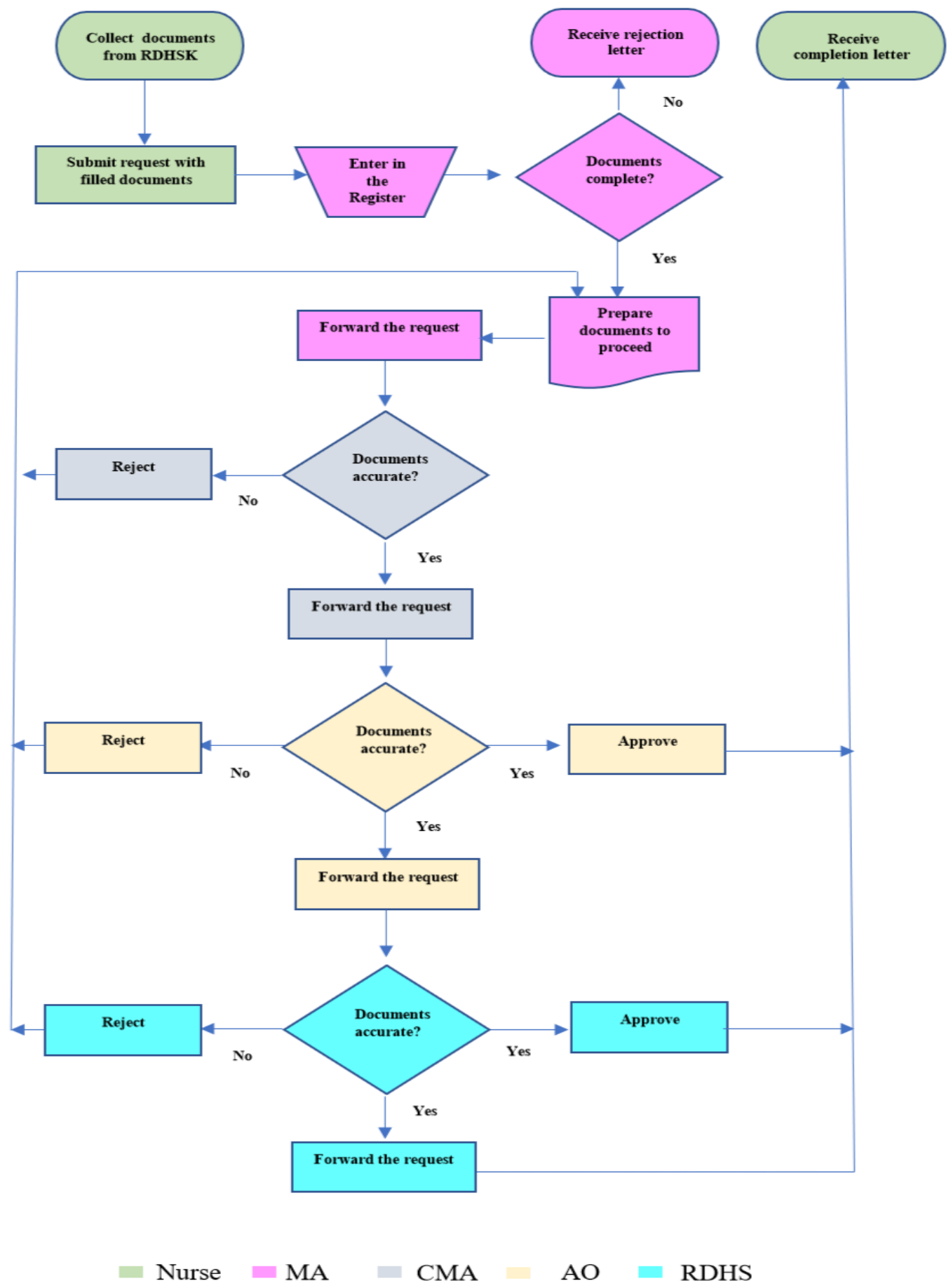

Figure 1: Process map of providing services to nursing officers at the Establishment Branch (EB) of Regional Director of Health Services' Office, Kurunegala (RDHSK) 


\title{
International Journal of Current Science Research and Review
}

\author{
ISSN: 2581-8341
}

Volume 05 Issue 01 January 2022

DOI: 10.47191/ijcsrr/V5-i1-31, Impact Factor: 5.825

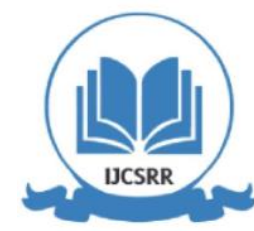

www.ijcsrr.org

language expert. The trilingual charter was made available at the EB with relevant MAs who take part in providing selected ten services and published on the official website of the RDHSK.

The selected ten services, the duration the RDHSK takes to fulfil the requested service (service delivery standard) in days and basic details on how to submit complaints and suggestions to the RDHSK were extracted from the finalized charter to make the summary charter. It was displayed at the entrance of the RDHSK and published on the official website along with the detailed charter.

Several supplementary interventions were developed to enhance the effectiveness of the charter. The list of documents that need to be submitted by the nursing officers to receive each requested service was extracted from the charter to develop document submission checklists. Going along the checklists, formats to be filled for receiving each selected service were compiled with a relevant checklist on the top. Formats compilations were made available at the main office of the nursing officers' work institute and the office of the Chief Nursing Officer (backup). There were two columns of boxes in checklists: the boxes dedicated for nursing officers are to be checked by the applicant nursing officer before submitting documents to the RDHSK and the other to be checked appropriately by MAs before receiving the documents at EB. A set of guidelines for nursing officers and their work institutions on new developments at RDHSK were developed and distributed to all health institutions where nursing officers are working. The work steps of redesigned processes were incorporated in a booklet for the use of MAs who take part in providing selected ten services at EB. The Medical Officer of the Quality Management Unit (MO-QMU) was appointed as the focal point by an internal circular of RDHS to ensure effective and sustainable implementation of the charter. A performance audit and a schedule for reviewing the charter every six months were fixed.

Half a day training was planned for the relevant staff of RDHSK, implemented and evaluated in between design and implementation stages with the objectives of educating the relevant staff of RDHSK on the importance of citizen's charter, making the relevant staff of the RDHSK aware of new developments introduced to the RDHSK and explaining the roles and responsibilities of the staff of RDHSK for effective implementation of the citizen's charter. Staff was provided with copies of the charter and the booklet on work steps for use following the half-day training.

\section{Promotion of the citizen's charter}

The bilingual summary charter was displayed at the entrance of RDHSK. The charter with supplementary documents was published on the official website of RDHSK (https://www.healthdept.nw.gov.lk/main_eng/kurunegala/downloads.php) allowing free access to service recipients. New developments were briefed by RDHS during the heads of institutions' meeting held in December 2019 at RDHSK. The charter was promoted through issuing an internal circular by RDHS to the heads of institutions where the nursing officers are working. In addition, two copies of charter and compiled format sets were distributed to all health institutions of RDHSK along with the internal circular through which the heads of institutions were advised to keep one each at the main office and the office of nursing-in-charge (back up). The principal investigator attended staff meetings at base hospitals under RDHSK making institutional staff aware of their role in the successful implementation of charter and related interventions.

\section{Service recovery}

The service recovery was carried out proactively and reactively. Relevant MA was entrusted to inform applicants with reasons when RDHSK is unable to fulfil standards, and contact details of responsible persons were indicated in the charter to be contacted by service recipients if things went wrong as proactive measures. If the applicant filed a complaint and there is a deficiency on the part of RDHSK, MO-QMU was assigned with the responsibility of apologizing with verbal explanations for non-delivery of service as stated in the charter, informing the status of the follow-up action to overcome the problem reactively.

\section{Monitoring}

Monitoring needs to be carried out continuously by the RDHS to ensure adherence to the pledges made in the charter. The monitoring mechanisms were designed to be carried out by already existing internal mechanisms as well as establishing a new feedback and response system. Complaints/feedback were encouraged to RDHSK through designed formats available at feedback box, the website with the charter and nursing officers' work institutions, by hand, post, fax or over the phone as per the contact details communicated through the charter and the complaints/feedback formats. The MO-QMU was entrusted with reviewing feedback weekly, issuing 


\title{
International Journal of Current Science Research and Review
}

\author{
ISSN: 2581-8341
}

Volume 05 Issue 01 January 2022

DOI: 10.47191/ijcsrr/V5-i1-31, Impact Factor: 5.825

IJCSRR@ 2022

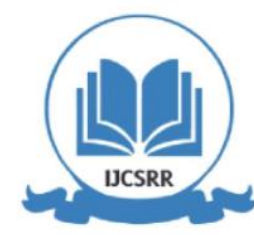

www.ijcsrr.org

the acknowledgement slips for the respondents of all feedback and recording in the feedback register. The MO-QMU implemented immediate remedial actions for negative feedback after consulting the RDHS and summarized and presented the positive feedback at the institutional quarterly quality reviews. The best performing staff members were appraised by RDHS at the quarterly quality review. The selection of such members was done by MO-QMU with the consensus of the steering committee based on customer feedback (highest number of positive feedback and lowest number of negative feedback) and the level of cooperation for implementing/sustaining the charter and related interventions. In addition to these existing internal mechanisms, a new feedback and response system consisting of citizen's feedback forms, a suggestion box, hotline services and client surveys were established. The relevant staff was trained by the principal investigator on handling and resolving problems faced by dissatisfied clients.

\section{Evaluation and improvement}

A steering committee comprising with DRDHS (Chair), MO-QMU (Secretary), AO and CMA (members) was established as per the circular issued by the Ministry of Public Administration to evaluate feedback, ensure that the grievance handling process is implemented systematically, and enable supervisors to monitor their subordinates closely. The committee was entrusted with planning, determining policy and implementation strategies, coordination, monitoring, evaluation and determining further efforts required to enhance the quality of outputs or services at the unit level. The RDHS was assigned with the responsibility to identify services that have not achieved the predetermined standards and their related problems, redefine standards for outputs or services to ensure that they are more realistic and achievable, identify types of outputs or services that can be expanded, curtailed or deleted without affecting the achievement of unit's objectives, and identify methods that could be used to further enhance the existing standards of services.

\section{RESULTS}

The citizen's charter for selected ten services provided by the EB to nursing officers, charter's sub-components and other supplementary components were developed to improve the service provision at the RDHSK. Sub-components include summary charter, and feedback and response system consisting of complaint and feedback formats, feedback box and feedback and response register. The supplementary interventions designed include document submission checklists, compilations of formats to be filled by applicants for ten services separately with a relevant checklist on top, guidelines for nursing officers and their work institutions on new developments and a booklet on work steps for service providing MAs at EB.

The trilingual citizen's charter was made available at the EB with relevant MAs who take part in providing selected ten services and published on the official website of the RDHSK. The bilingual summary charter was displayed at the entrance of RDHSK as well as the official website of the RDHSK. The active feedback and response system was newly established for monitoring the charter initiative with a feedback box at the entrance of the RDHSK adjacent to the displayed summary charter. The complaint/suggestion formats were made available at the feedback box, the website with the charter, and the main office and the office of in-charge nursing officers of nurses' work institutions, to be sent by hand, post, fax or over the phone to the RDHSK.

The complaints/suggestions register was designed and made available at the QMU. The MO-QMU was entrusted with entering the complaints/suggestions received, issuing acknowledgement slips for all feedback received, reviewing feedback weekly, implementing immediate remedial actions with RDHS and recording in the register. The monitoring was partly incorporated into the existing mechanism of quarterly quality reviews of RDHSK. The appraisal mechanism selects and praises the best performing member/s quarterly at institutional quality review. The focal point and steering committee were appointed through internal circulars of RDHSK. The focal point for successfully implementing and monitoring the charter is QMU. The steering committee for the charter comprising with the Deputy RDHS (Chair), the MO-QMU (Secretary), the AO and the CMA (members) ensures the evaluation and improvement mechanisms through planning, determining policy and implementation strategies, coordination, monitoring, evaluation and determining further efforts required to enhance the quality of services at the unit level. The RDHS bears the overall responsibility of improving the charter and related interventions without affecting the achievement of the objectives EB.

\section{DISCUSSION}

The citizen's charter for selected ten services provided by the EB of RDHSK to nursing officers, charter's sub-components and other supplementary components were developed to improve the service provision at the RDHSK, adopting a participatory approach. 


\title{
International Journal of Current Science Research and Review
}

\author{
ISSN: 2581-8341
}

Volume 05 Issue 01 January 2022

DOI: 10.47191/ijesrr/V5-i1-31, Impact Factor: 5.825

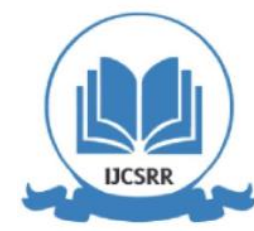

$\underline{\text { www.ijcsrr.org }}$

Instead of trying to reform all the processes at once and encounter massive resistance, it was decided to initiate formulating a charter for one branch and expand to others gradually. As the EB serves the largest customer category of nursing officers with routine personal file related services and service providers of EB were searching for novel solutions to overcome the numerous issues they faced during service provision, the EB was the easiest place to initiate implementing the charter in RDHSK.

Process mapping is a way of reviewing existing processes for improving them and increasing the efficiency and effectiveness of service provision.[13] Process mapping was done to identify deficiencies in service provision to nursing officers at EB. The functional flow extended from collecting formats by nursing officers from RDHSK up to the receipt of completion/rejection letter by the applicant.

Charters must be developed in a participatory way. Hence, service providers who would finally implement it as well as service receivers were involved from the planning stage throughout. Interventions were planned considering cost-effectiveness, time, administrative feasibility and sustainability while not disturbing the routine flow of documents. As succeeded by Adhikari[14], staff acceptability was considered a significant decision factor during planning. All actions were implemented with full stakeholder participation. Initial doubts of RDHSK staff and nursing officers were overcome by explaining to them the benefits of new developments. People who resisted web-based versions were allowed to continue with the paper-based system.

Citizen's charter initiative is a response to the mission for solving the problems which a citizen faces day to day while dealing with the organizations providing public services. Formulation and implementation of the citizen's charter proceeded as guided by the circular on the introduction of the citizen's charter issued by the Ministry of Public Administration in 2008, paying special attention to the possible reasons for failures. Lack of explicit service standards for the EB of RDHSK resulted in unacceptable delays in service provision and frequent unwarranted visits were dealt with establishing service standards. The ineffective two-way communication between the EB and service recipients that builds a dilemma among service recipients on documents to be submitted along with requests was solved by listing such documents needed for receiving each service in the citizen's charter. The effective feedback and response system helped tackle customer grievances on poor service provision and receive nursing officers' suggestions for improving service provision matching customer expectations. To supplement the effectiveness of the charter and its subcomponents through rectifying inefficiencies found in the processes, four supplementary interventions were also designed. Submitting incomplete documents for receiving services by applicant nursing officers was corrected by checklists. The compiled sets of formats with checklists on top were sent to nursing officers' working institutions to assure easy accessibility. Booklet on work steps intended to make aware MAs of cover-up duties in the absence of relevant MAs and to minimize the impact on standards during transfers or new MA appointments.

The concept of charter safeguards the trust between the service provider and service recipients. There may be instances where the EB is not able to fulfil the pledges made in the charter. Should this happen it would adversely affect the image and credibility of the EB and the EB must take immediate appropriate action to restore the faith of the citizens. This process is called service recovery. The feedback and response register was designed in a way to facilitate the monitoring of the grievance redress mechanism with separate sections for complaints, suggestions and praises, and the columns in each section. The charter was made available trilingual to assure equity in service provision. The orientation of staff about the salient features and goals/objectives of the charter; vision and mission statements of the institution; and relevant skills such as handling grievances of unsatisfied customers is vital for successful implementation of the charter. A systematic training was hence planned, implemented and evaluated before implementing the charter and related new developments.

The charters need wider publicity to gain wider awareness about the citizen's charter among service recipients as well as service providers. Hence, the charter was promoted through multiple methods. As the customer segment of the developed charter belongs to a specific group, the promotion was relatively easier than publicizing a charter among the general public.

The charter initiative should have a mechanism for monitoring, evaluating and review of the working of the charter both internally and externally, preferably through an outside agency. Internal mechanisms were established for monitoring, review and evaluation while paying attention to utilizing already established mechanisms to assure sustainability. New mechanisms were established where appropriate. Negative as well as positive feedback is extended to the EB where negative feedback would demand an immediate remedial action while positive feedback conveys a sense of appreciation. To counteract any unintended effects from the negative 


\section{International Journal of Current Science Research and Review}

ISSN: 2581-8341

Volume 05 Issue 01 January 2022

DOI: 10.47191/ijesrr/V5-i1-31, Impact Factor: 5.825

IJCSRR@ 2022

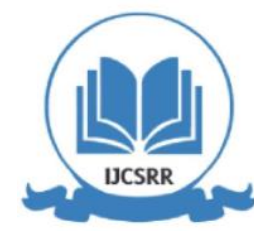

www.ijesrr.org

feedback, care was taken to ensure that positive feedback is also conveyed to all the staff through quarterly quality reviews. This would ensure that the motivation level of the staff is not adversely affected.

\section{CONCLUSION}

The citizen's charter is a tool to improve the service provision at RDHS offices. The participatory approach, involvement of all stakeholders throughout the process, wider publicity of the charter among service recipients as well as service providers, effective feedback and response system, and establishing mechanisms for monitoring, evaluation and review of the working of the charter initiative both internally and externally are useful means to successfully develop and sustain charters. Supplementary interventions may be designed to supplement the effectiveness of the charter depending on the issues concerning the service provision.

\section{REFERENCES}

1. Ministry of Health, Sri Lanka. 2021. Annual Health Statistics 2019: Sri Lanka, Ministry of Health, Sri Lanka, Available from: http://www.health.gov.lk/moh_final/english/public/elfinder/files/publications/AHB/AHS\%202019.pdf

2. World Bank. 2010. How-to notes Citizen Charters: Enhancing service delivery through accountability Available from: https://documents1.worldbank.org/curated/en/543241468135929562/text/638900BRI0Citi00Box0361531B0PUBLIC0.txt

3. Organisation for Economic, Co-operation and Development. 2018. Governance - Organisation for Economic Co-operation and Development, OECD: Better politics for better lives. Available from: https://www.oecd.org/mena/governance/citizencharters-tunisia.htm

4. Ministry of Public Administration and Home Affairs, Sri Lanka. 2008. Introduction of the Citizens'/Clients' Charter. Available from: https://www.pubad.gov.lk/web/images/circulars/2008/E/05-2008(e).pdf

5. OECD et al. 2007. Improving customer orientation through Service Charters: A handbook for improving quality of public services. Available from: https://www.govint.org/fileadmin/user_upload/publications/Improving_Customer_Orientation_ through_Service_Charters.pdf

6. Civilsdaily. Citizen's Charter: Importance, objective, features, problems faced in implementation, Guidelines Civilsdaily. 2022. Available from: https://www.civilsdaily.com/citizens-charter-importance-objective-featuresproblems-faced-in-implementation-guidelines/

7. Shankar HPS. n.d. Citizen's Charters: An empirical study. Available from: http://atimysore.gov.in.

8. G K Today.2021. Concept, Origin and Principles of Citizen's Charters, Available from: https://www.gktoday.in/topic/concept-origin-and-principles-of-citizens-charters/

9. Huque A. 2016. Citizen's Charter and implementation failure: Performance of Local Councils in Bangladesh.

10. European Public Administration Network. 2008. Seven steps to a Citizen Charter with service standards: Implementation plan for governmental organizations practitioners handbook. Available from: https://www.eupan.eu/wpcontent/uploads/2019/05/2008_2_FR_Seven_Steps_to_a_Citizen_Charter_with_Service_Standards.pdf

11. Thomassen J-P, Ahaus K, Van de Walle S, Nabitz U. 2014. An Implementation Framework for Public Service Charters: Results of a concept mapping study. Public Manag Rev, 19;16. Available from:

https://www.researchgate.net/publication/263611910_An_Implementation_Framework_for_Public_Service_Charters_R esults_of_a_concept_mapping_study

12. Gamage CJK. 2018. Enhancing public service delivery: A study of Citizen's Charter practice in Galle District Sri Lanka.

13. US Department of Housing and Urban Development. 2021. Improving performance with process mapping. Available from: https://www.hudexchange.info/resource/4535/improving-performance-with-process-mapping

14. Adikari AMPS. 2018. A project to improve human resource record management system of nurses in a Teaching Hospital, Published thesis, Postgraduate Institute of Medicine, Colombo, Sri Lanka

Cite this Article: Rajakaruna, I.M.S.M., Krishanth, M.D.A., Pathirage, I.D., Arnold, S.M. (2022). Development of Citizen's Charter to Improve the Service Provision at a Regional Health Services Directorate in Sri Lanka. International Journal of Current Science Research and Review, 5(1), 267-274 